\title{
Análise da Interatividade em Sites de E-commerce
}

\author{
Interactivity analysis on e-commerce websites
}

\author{
BORTOLÁS, Natália Ordobás; Mestranda; \\ Universidade Federal de Santa Catarina - UFSC \\ nbortolas@gmail.com
}
GONÇALVES, Berenice; Doutora em Engenharia de Produção Universidade Federal de Santa Catarina - UFSC berenice@cce.ufsc.br

\author{
VIEIRA, Milton Horn; Doutor em Engenharia de Produção \\ Universidade Federal de Santa Catarina - UFSC \\ milton@cce.ufsc.br
}

\begin{abstract}
RESUMO
O presente artigo busca identificar os tipos, as especificidades e o nível de interatividade em interfaces de sites de e-commerce. A interatividade é intrínseca ao processo de interação social bem como à comunicação homem-máquina. A interação humano-computador busca no processo de interação social inspiração para otimizar a interatividade em interfaces virtuais. Assim, neste estudo, buscou-se conceitos de interatividade que orientassem o exame da interface com base em um método de avaliação por inspeção. Partindo-se dos critérios propostos por Rhodes \& Azbell, Rafaelli, Sims, Laurel, e Lemos, entende-se que a interatividade do ambiente digital observado está no nível Reativo, tendo como característica a navegação não-linear. Também foi identificado que as respostas do sistema às ações do usuário são pré-configuradas de forma genérica, sendo este um limitador na individualização da troca de mensagens entre usuário e sistema.
\end{abstract}

Palavras-chave: Interatividade, Interface, Comunicação Humano-Computador.

\begin{abstract}
This article aims at identifying types, specificities and interactivity levels on e-commerce website interfaces. Interactivity is intrinsic to the process of social interaction as well as human-machine communication. The human-computer interaction seeks inspiration in the social interaction process in order to optimize interactivity in virtual interfaces. In this study, interactivity concepts that guided the interface examination based on an evaluation method through inspection were looked for. With criteria proposed by Rhodes \& Azbell, Rafaeli, Sims, Laurel, and Lemos, can be inferred that the digital environment interactivity is observed in reactive level, with a non-linear navigation feature. It was also identified that system responses to user actions are preconfigured in a generic way, which becomes a limitation to individualize message exchanges between user and system.
\end{abstract}

Key-words: Interactivity, Interface, Human-Computer Communication. 
Análise da Interatividade em Sites de E-commerce

\section{INTRODUÇÃO}

A sociedade, hoje, é incentivada pelo desenvolvimento das Tecnologias de Informação e Comunicação. Tem passado por transformações que se relacionam ao modo de acessar as informações, à quantidade e ao fluxo desses dados (PASSOS; MOURA, 2007). A Internet é um dos veículos indispensáveis nesse processo, pois muitas tecnologias se utilizam dela para a propagação de dados.

Tarefas exclusivamente realizadas no mundo físico, passaram também a ser realizadas no meio virtual, impulsionadas, principalmente, pelo surgimento da Internet e da Web. Nesse sentido, as compras online tem crescido e, especificamente no Brasil, aponta-se que a metade da população tem acesso à Internet e que quase a metade dessa parcela realiza compras online (INFO ONLINE, 2011). Ainda assim, os empreendimentos comerciais na Web passaram por momentos críticos, justificado, em parte, pelo design insatisfatório de interfaces (AGNER, 2006).

Nessa perspectiva, à medida em que surgem novas formas de interações, estudos na área do Design de Interação e Interatividade tornam-se necessárias. Mas, mesmo que muitas pesquisas já estejam sendo realizadas nessa área, principalmente no Design de Interação, não é comum encontrar na Web interfaces de Websites que se baseiem nesses estudos. Fala-se muito em interatividade, mas poucas aplicações relacionadas à interação estão sendo utilizadas em projetos para a Web.

Assim, no presente estudo, buscou-se identificar os tipos e o nível de interatividade de uma interface de sites de e-commerce. Para alcançar este objetivo, realizou-se o levantamento dos elementos interativos de três websites na modalidade comércio eletrônico, especificamente no processo de identificação/avaliação do produto (ação realizada pelo usuário). O website com maior quantidade de elementos interativos foi selecionado e examinado a partir de uma avaliação, a qual abordou os objetivos do usuário e objetos da interface. Tal método também pode diagnosticar problemas que os usuários possam encontrar na interface durante a interação, o que possibilitou apresentar sugestões que otimizem a interatividade em interfaces voltadas para as compras online.

Ao citar Fleming, Agner (2006) observa que para um site ser bem sucedido é necessário existir "suporte adequado às intenções e ao comportamento do usuário". Uma estratégia bem empregada em um site pode ser totalmente errada para outro. Assim, "compreender quais são essas intenções e comportamentos seria a etapa mais importante do design" (AGNER, 2006, p. 49).

Após essa primeira seção de caráter introdutório, a seção dois tratou da fundamentação teórica, contemplando um estudo sobre E-Commerce, Interface/Interação Humano-Computador, Interação e Interatividade. A seção três explicitou os procedimentos metodológicos desse relatório, e a seção quatro relatou a análise das interfaces. A seção cinco e seis apresentaram, respectivamente, os resultados e discussões, e conclusões.

\section{FUNDAMENTAÇÃO TEÓRICA}

\subsection{Economia na Internet}

Boa parte do processamento de informações é feita entre computadores. A Internet, como um veículo da propagação dessas informações, foi palco para muitas empresas otimizarem seus empreendimentos, principalmente no ramo do comércio eletrônico. Agner (2006) explica que, por volta do final da década de 1990, o design insatisfatório de interfaces acarretou diversos custos para as companhias online: uma perda de quase $50 \%$ das vendas - clientes não conseguiam encontrar produtos ou informações -, e o resultado negativo da primeira visita ao site, que contribuía para a perda de $40 \%$ dos clientes.

O início do século XXI foi período de reavaliação das estratégias desenvolvidas para o comércio na Web. E, com a evolução da tecnologia móvel - como os netbooks, smartphones e tablets -, otimizouse e popularizou-se o acesso à Internet. Tarefas realizadas exclusivamente no meio físico eram inseridas também no meio virtual. Tais ações facilitavam e aceleravam a busca por informação e comunicação, o que veio a intensificar o desenvolvimento do comércio eletrônico. 
Uma pesquisa da Fecomércio-RJ/Ipsos aplicada a 1000 entrevistados em 70 cidades de regiões metropolitanas brasileiras, divulgada no dia 08 de novembro de 2011 pela Info Online (2011), aponta que o percentual de brasileiros conectados à Internet passou de $27 \%$ para $48 \%$ entre os anos de 2007 e 2011. A pesquisa também informa que o avanço da tecnologia contribuiu para esse crescimento. Além disso, aumentou de $13 \%$ para $20 \%$, de 2007 a 2011, o número de brasileiros que fazem compras online. Dos entrevistados, $38 \%$ apontam que a comodidade é a maior vantagem das compras online, $33 \%$ afirmam que os preços são melhores, e $11 \%$ acreditam que há maior facilidade na pesquisa feita na Web. No ano de 2011, as formas de pagamento mais comuns nas compras na Web eram com cartão de crédito (66\%) e boleto bancário (28\%). Além disso, $62 \%$ dos entrevistados ainda informam que usam a Internet em casa. Abaixo, na Figura $X$, estes mesmos dados podem ser visualizados em forma de infográfico, a fim de facilitar a leitura das porcentagens levantada em cada item da pesquisa.

\subsection{Interface e Interação Humano-Computador}

Inicialmente, quando surgiu o conceito de Interface, ela era entendida "como o hardware e o software com o qual o homem e o computador podiam se comunicar" (ROCHA; BARANAUSKAS, 2003 , p.07). Apresentando uma ampliação no conceito, para Coelho (2008, p. 207), a interface é entendida como uma "superfície limítrofe entre dois corpos ou espaços". Ainda segundo o autor, a interface "vai além de uma simples separação; indica a possibilidade de adaptação, de interconexão, de COMUNICAÇÃO entre dois ou mais sistemas, equipamentos, unidades etc., que de alguma forma, apresentem diferenças ou incompatibilidades funcionais". Complementa-se com a ideia de Rocha e Baranauskas (2003) que a evolução do conceito de interface incluiu os aspectos cognitivos e emocionais do usuário no processo de comunicação.

Uma das partes essenciais de um Website ou aplicativo hipermídia é a sua interface, pois nela há "estímulos e informações" que estabelecem "o trânsito de elementos entre o real e o digital" (MOURA, p. 60, 2007). Com o crescente valor da informação, disseminação da informática e expansão da área de Web Design (REDIG, 2004), a interface digital apresenta-se como elemento central na concepção de produtos virtuais. E tal concepção está estritamente relacionada com as possibilidades de interação entre usuário e produto. As interfaces digitais, então, buscam basicamente aprimorar a experiência e interação entre usuário e produto.

Dessa forma, como mostra a Figura 1, a Interface/Interação Humano-Computador pode ser definida como a interação entre o homem e a máquina. Essa interação ocorre graças à superfície limítrofe entre estes dois corpos, que é a interface, a qual vai indicar a forma de comunicação entre humano e computador e buscar uma adaptação para mediar as diferenças ou incompatibilidades funcionais existentes entre estes dois elementos.

Figura 1 - Ilustração representando a comunicação entre homem e máquina

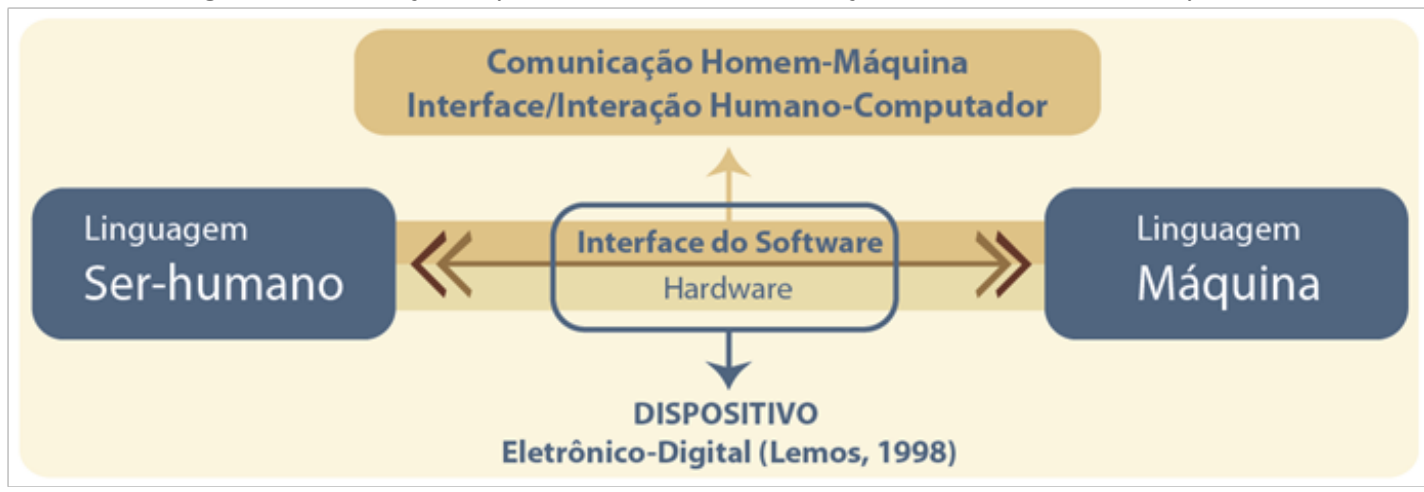

\subsection{Interatividade versus Interação}

Interatividade e Interação são termos utilizados praticamente como tendo o mesmo significado. Entretanto, de acordo com Ferrera (2008) é necessário distinguir cada termo, a fim de aplicá-los 
Análise da Interatividade em Sites de E-commerce

da forma mais adequada. Segundo o mesmo autor, ao citar o dicionário da Língua Portuguesa, da Porto Editora, o verbete interação (substantivo) provém da junção "inter" e "ação", significando ação (ou atualização da influência) recíproca de dois ou mais corpos uns nos outros ou entre usuário e equipamento. O verbete interatividade (substantivo) provém da soma de "inter" e "atividade, ou do inglês interactivity. Ele significa comunicação recíproca, sendo a possibilidade de interação entre indivíduos ou elementos de um sistema ou ainda, é definido como o grau de intervenção do usuário com dados e comandos acionados em uma máquina. Ferrera (2008) justifica, então, que a palavra interatividade vem de interativo e que este provém da união de "inter" e "ativo", sendo um adjetivo. É aquilo que permite ou é capaz de interação.

De acordo com Santaella (2004, p. 152), o termo interatividade é definido como a "análise sobre a relação entre usuários humanos e aplicações informáticas de natureza conversacional". O termo também transmite ideia de bidirecionalidade, sendo que a comunicação opera em dois sentidos, interindividual ou intergrupal. A autora ainda afirma que a interatividade está aproximada semanticamente das palavras ação (operação, trabalho, evolução), agenciamento (intertrabalho), correlação (influência mútua) e cooperação (contribuição, coagenciamento, sinergia e simbiose), das quais empresta seus significados.

Na tradução de Ferrera (2008), Steuer (1993) afirma que interatividade não é verbo (ação), nem adjetivo (qualidade), mas sim o substantivo que nomeia uma propriedade ou condição de interação. Rafaeli (1988) contribui para um dos diversos conceitos de interatividade ao afirmar que ela é uma característica variável da configuração da comunicação. Para que a interatividade aconteça por completo, os papéis da comunicação precisam ser intercambiáveis.

Mesmo tendo sido observada a opinião de alguns autores a respeito do conceito de interatividade, e considerando-se que existem diversos outros conceitos abordando o assunto, nota-se que não há um consenso sobre o que realmente define o termo. Moraes (1998) observa que a literatura sobre interatividade é escassa, não havendo tampouco livros específicos sobre o tema, o qual é bastante abordado e utilizado, mas são poucos os textos que se propõem a discuti-lo sistematicamente.

Dessa forma, em pesquisa sobre mídias computacionais, interatividade é um termo central e recorrente, porém sem consenso conceitual ou paradigma estabelecido (SIMS, 1997; JENSEN, 2005; MORAES, 1998; FERRERA, 2008). Coube, então, fazer uma distinção sobre interatividade e interação e citar os autores que mais se enquadram neste relatório, evitando a análise aprofundada de cada conceito sobre Interatividade.

\subsection{Classificações de Interatividade}

Existem classificações ou níveis de interatividade propostos por diversos autores, como Rhodes \& Azbell (1985), Rafaeli (1988), Laurel (1991), Steuer (1993), Schwier \& Misanchuk (1993), Sims (1997), Lemos (1999), Primo e Cassol (1999), Primo (2003, 2007), Nassar e Padovani (2011) etc. Assim, a partir de uma análise preliminar, elegeu-se cinco abordagens para aprofundamento. Dessa forma, as classificações e nível de interatividade apresentados a seguir expõem as proposições de: Rhodes \& Azbell (1985), Rafaeli (1988), e Laurel (1991 apud Tori, 2008), Sims (1997) e Lemos (1999).

\subsubsection{Rhodes \& Azbell (1985 apud Sims, 1997):}

De acordo com Sims (1997), Rhodes \& Azbell propuseram três níveis de interatividade: Reativo, Coativo e Proativo. O nível Reativo define o pouco controle do usuário na estrutura do conteúdo. 0 Coativo, sendo um nível intermediário, proporciona ao usuário controle da sequência, estilo e ritmo, chegando ao Proativo, onde o usuário controla tanto a estrutura quanto o conteúdo. Os autores definem esses níveis, representados na Figura 2, a partir do estudo de interfaces de programas instrucionais, ou seja, voltadas para o ensino à distância. Entretanto, por focarem sua análise na interação do aluno com a máquina, foi possível utilizá-la de uma forma mais ampla, identificando o aluno como usuário e a máquina, como qualquer programa digital, software aplicativo, sistema online ou website.

Figura 2 - Níveis de Interatividade proposto por Rhodes \& Azbell (1985 apud Sims, 1997). 
NÍVEIS DE INTERATIVIDADE (Rhodes \& Azbell, 1985, apud Sims, 1997)

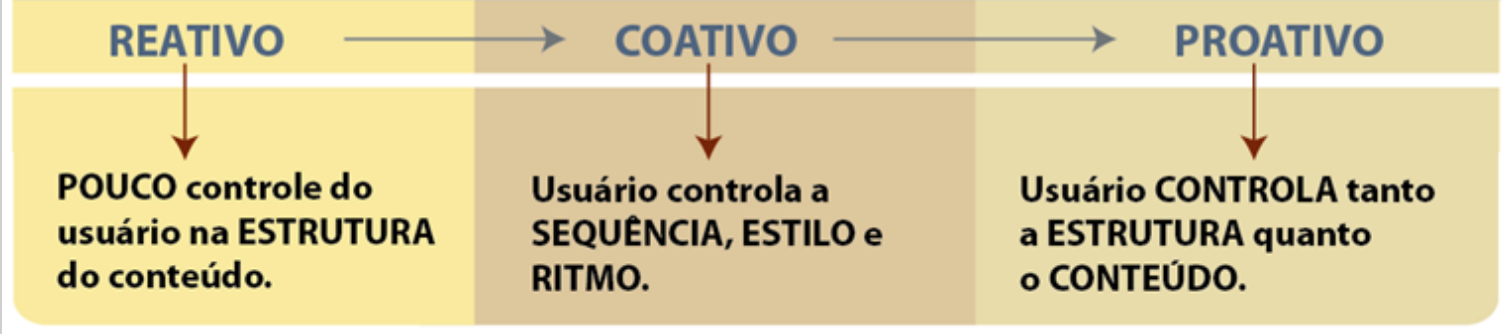

\subsubsection{Rafaeli (1988):}

O autor busca contribuir para a construção da validação da interatividade como uma variável. Para ele, a interatividade é uma necessidade básica do ser humano, sendo, então, mais que uma condição do processo de comunicação. Assim, nas palavras de Ferrera (2008, p.64), "No seio dessa visão a interatividade é uma quantidade, isto é, é uma variável quantificável, não apenas uma condição."

Dessa forma, cita-se, dentre muitas, uma série de características que definem a interatividade em um ambiente virtual: Bidirecionalidade, Resposta imediata, Controle do usuário, Resposta (Feedback), Transparência, Inteligência Artifical etc. A fim de especificar o significado de cada item, buscou-se definir cada um dos seus conceitos a partir do Moderno Dicionário da Língua Portuguesa Michaelis Online (Michaelis - Uol, 2009):

- Bidirecionalidade - "Bidirecional": (bi + direcional) Que é reativo ou funciona em duas direções, comumente opostas.

- Resposta Imediata - "Imediato": Que não tem nada de permeio, que é consecutivo, próximo, contíguo, instantâneo.

- Controle do usuário - "Controle": É o ato de dirigir qualquer serviço, fiscalizando-o e orientanto-o do modo mais conveniente.

- (Feedback) "Resposta": É a ação ou efeito de responder. Aquilo que é dito ou escrito para responder a uma pergunta. O que decide, o que explica alguma coisa; solução.

- Transparência - "Transparente": No sentido de ser claro, evidente, que se percebe facilmente. Assim, a característica de transparência, no âmbito de interfaces digitais, pode ser entendida como a facilidade de perceber as ações que podem ser realizadas pelo usuário. Um exemplo disso seriam os hiperlinks (elementos de interação), que devem ser claros e fáceis de serem identificados. Outro exemplo seriam os caminhos da navegação, se são fáceis de serem percebidos, se estão organizados, se são fáceis de interpretar aonde estão "levando" o usuário.

- "Inteligência Artificial": De acordo com Gomes (2011), a inteligência artificial pode envolver pensamento e raciocínio, quando é definida como "sistemas que pensam como seres humanos" ou quando é definida como "sistemas que pensam racionalmente". Ela também pode envolver comportamento quando significa "sistemas que atuam como seres humanos" ou quando significa "sistemas que atuam racionalmente".

\subsubsection{Laurel (1991 apud Tori, 2008):}

De acordo com Tori (2008), a interatividade é o somatório de atividades, nas quais considerase: Frequência, Abrangência ou Amplitude (NASSAR; PADOVANI, 2011) e Significância, mostradas na Figura 3. Segundo Nassar e Padovani (2011), a Frequência define em que momentos o usuário pode 
Análise da Interatividade em Sites de E-commerce

agir, a Abrangência (ou Amplitude) define quantas escolhas o sistema disponibiliza ao usuário e a Significância envolve a importância das escolhas do usuário.

Figura 3 - Interatividade como somatório de três atividades (Laurel, 1991 apud Tori, 2008)

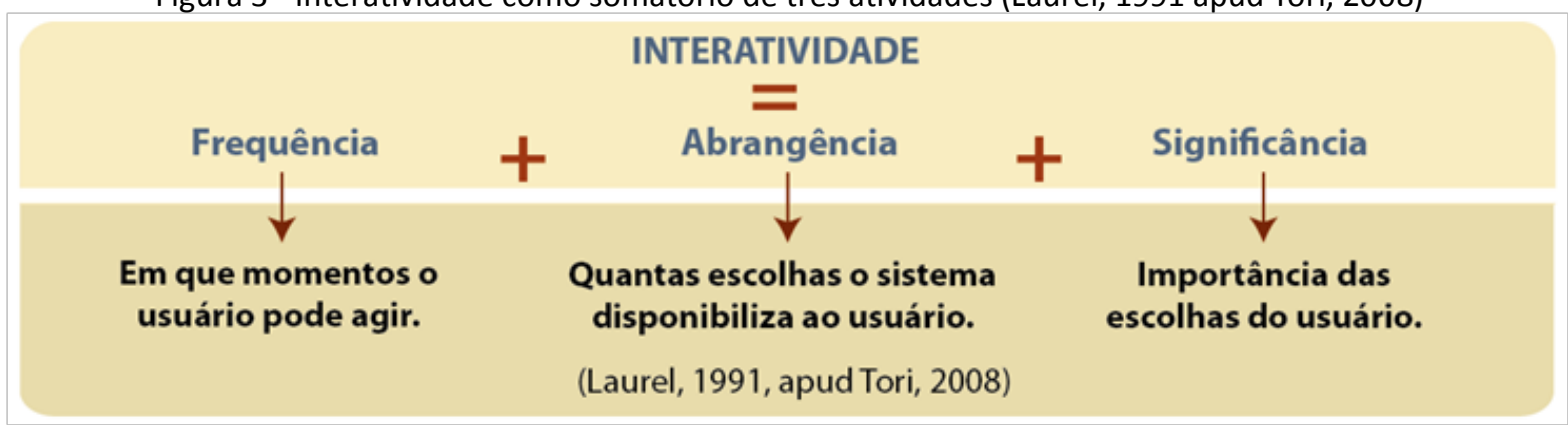

\subsubsection{Sims (1997):}

A classificação deste autor é proposta como um guia para identificar os tipos de interatividade que estão presentes em um programa instrucional, ou seja, em um ambiente virtual de aprendizagem. Uma vez que algumas dessas classificações podem ser utilizadas na interatividade de qualquer outro sistema (apresentam foco na navegação e feedback do sistema), oito dos dez itens propostos por Sims foram tratados neste relatório. Os dois itens que não foram expostos, Interatividade Refletida e Interatividade de Simulação, tem aplicação específica em programas instrucionais, não sendo aplicável em outros sistemas digitais.

1. Interatividade do Objeto (Object Interactivity): refere-se a uma aplicação em que os objetos (botões, pessoas, coisas) são ativados usando o mouse ou outro dispositivo apontador. Quando um usuário clica no objeto, haverá um tipo de resposta audio-visual.

2. Interatividade Linear (Linear Interactivity): refere-se a aplicações nas quais o usuário está hábil a mover (para frente e para trás) através de uma sequência linear pré-determinada de um conteúdo. Esse tipo de interação não oferece um retorno a respostas específicas para as ações do aprendiz, mas, simplesmente, oferece acesso para a próxima (ou anterior) tela na sequência.

3. Interatividade de Suporte (Support Interactivity): um dos componentes essenciais de qualquer software aplicativo é a facilidade do usuário de receber suporte no desempenho de suas tarefas, o que pode ir de uma simples mensagem de erro a um complexo tutorial do sistema. A inclusão da interatividade de suporte nesta classificação estende às opções do desenvolvedor de incluir tanto um suporte generalizado quanto um suporte sensível ao contexto.

4. Interatividade de Atualização (Update Interactivity): uma vez que Sims (1997) apresenta como objeto de estudo os ambientes virtuais de aprendizagem, os exemplos e conceitos sobre essa classe de interatividade tratam explicitamente da comunicação entre aluno e programa instrucional. Dessa forma, de acordo com Primo e Cassol (1999), essa classe refere-se às circunstâncias de diálogo entre aluno e conteúdo gerado pelo computador. Para este conceito, as aplicações apresentam ou geram problemas (a partir de um banco de dados ou em função da performance do aluno) ao qual o próprio aluno deve responder; a análise de resposta resulta na atualização ou resposta gerada pelo computador. Interatividade de atualização pode acontecer desde uma simples estrutura perguntaresposta até respostas condicionais complexas, as quais podem incorporar componentes de inteligência artifical. Quanto mais a Atualização é baseada em respostas recentes dos alunos, mais individualizadas estas atualizações irão aparecer. A partir dessa classe pode-se entender que em qualquer interação usuário-máquina a interatividade de atualização é fundamental, à medida em que a ação (pergunta) do usuário gera um retorno (resposta) da máquina. Essa "pergunta-resposta" pode ser simples ou complexa e, neste caso, gerar componentes de inteligência artificial, bem como apresentado por Sims em sua proposta.

5. Interatividade de Construção (Construct Interactivity): é uma extensão da Interatividade de Atualização, e requer a criação de um ambiente virtual em que o usuário possa manipular objetos 
dos componentes do sistema computacional a fim de alcançar objetivos específicos.

6. Interatividade de Hiperligação (Hyperlinked Interactivity): nessa classe, o usuário tem acesso a uma riqueza de informações, podendo navegar à vontade por essa base de conhecimento. A navegação pelo labirinto de informações deve ser adequada: na perspectiva dos desenvolvedores, o maior esforço do design de interfaces envolve definir, manter e integrar os hiperlinks apropriados a fim de garantir que as possibilidades ou caminhos relevantes são acessíveis ao usuário.

7. Interatividade Contextual Não-Imersiva (Non-Immersive Contextual Interactivity): esse conceito combina e estende os vários níveis de interatividade em um ambiente virtual. O usuário, então, pode se envolver em um ambiente com conteúdos bem elaborados e que apresentam significado adequado na interface.

8. Interatividade Imersiva Virtual (Immersive Virtual Interactivity): frequentemente percebida como o último nível na interação, a interatividade imersiva virtual proporciona um ambiente interativo onde o usuário é projetado em um mundo completo gerado pelo computador, onde existem respostas a movimentos e a ações individuais.

\subsubsection{Lemos (1999) :}

Este autor categoriza a interface em três dimensões, que são a Interação Social, a Interação Técnica tipo Analógico-Mecânica e a Interação tipo Eletrônico-Digital (Figura 4). Para Lemos (1999, p. 01), os objetos analógicos (interação analógico-mecânica), como a maçaneta de uma porta, reage de uma forma passiva, enquanto que os novos objetos eletrônicos digitais (interação eletrônicodigital) interagem de forma ativa, pois há um "diálogo constante entre os agentes". Assim, a noção de interatividade está ligada às novas tecnologias ou "às novas media digitais". Essa compreensão de interatividade "nada mais é do que uma nova forma de interação técnica, de cunho 'eletrônico-digital', diferente da interação ‘analógica' que caracterizou os media tradicionais” (LEMOS, 1999, p. 01).

Figura 4 - Dimensões da Interatividade propostas por Lemos (1999)

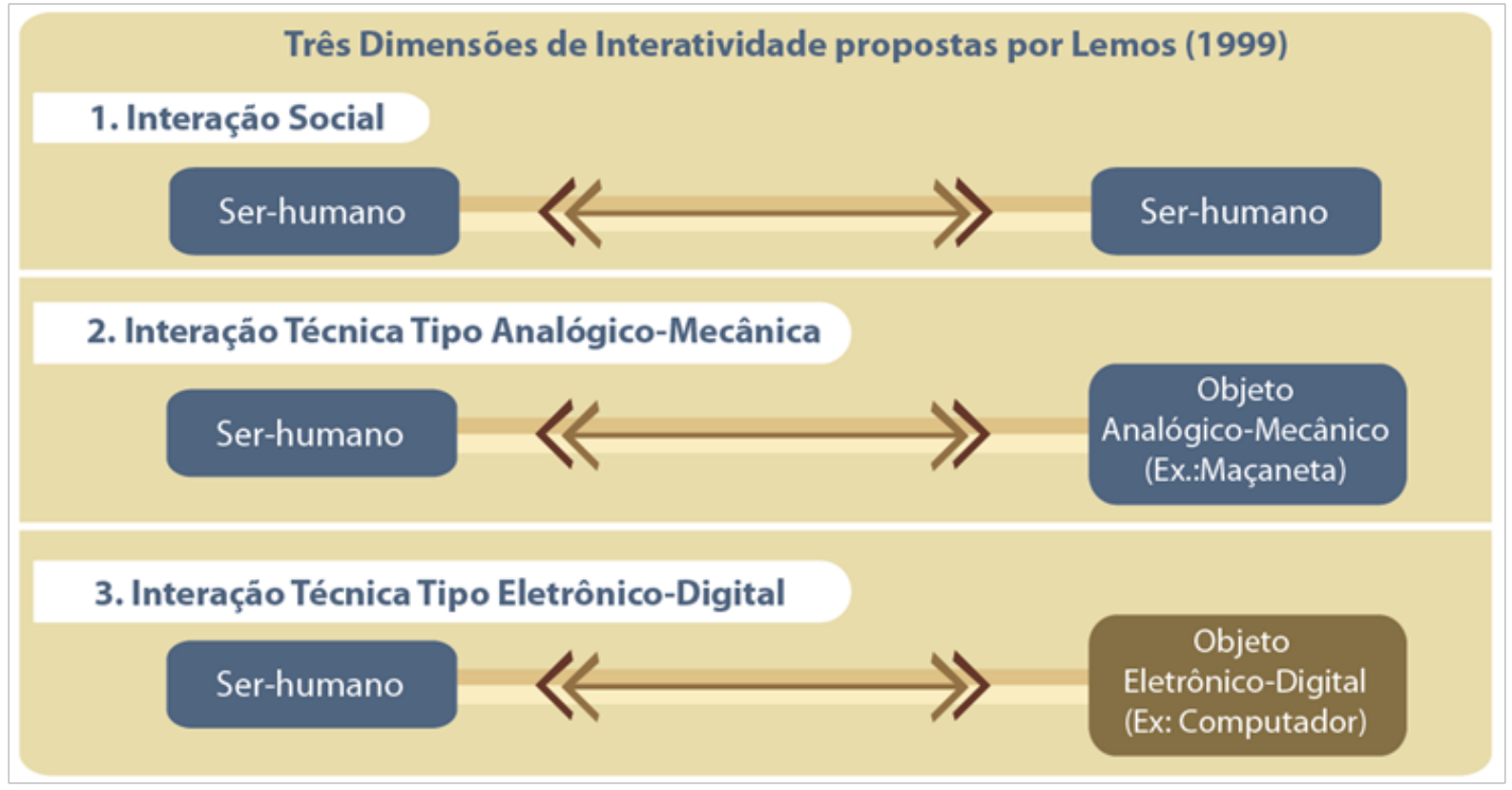

\section{PROCEDIMENTOS METODOLÓGICOS}

Esta etapa da pesquisa envolveu a definição de três Websites da modalidade e-commerce. Os sites são de supermercados, atuantes na cidade de Florianópolis e que apresentam a opção de compras online. A escolha por este objeto de estudo é justificada pelo fato de que produtos alimentícios, higiênicos, de limpeza, ou outros produtos de ordem doméstica são consumidos periodicamente e 
Análise da Interatividade em Sites de E-commerce

que, em muitos casos, a escolha de compra destes produtos depende de sua embalagem: tamanho, forma, cores, informações, e outros. A escolha do produto dentro de um supermercado envolve o contato com interfaces físicas, envolve os sentidos, como visão, olfato, e tato. E, como nem todos estes sentidos são contemplados no mundo virtual, os desafios em definir interações satisfatórias no meio digital são diversos e mais complexos, porém não menos importantes.

Para definir quais os supermercados seriam inspecionados, fez-se, primeiramente, uma busca online dos supermercados existentes em Florianópolis. Foram encontrados os seguintes estabelecimentos: Hipermercado Big, Supermercado Imperatriz, Supermercado Angeloni, Supermercado Hippo, Supermercado Comper, Nacional Supermercados, Bistek Supermercados, e Supermercados Rosa.

A partir de uma busca online pelos sites de cada estabelecimento, pode-se constatar que apenas três dos oito estabelecimentos pesquisados apresentam a opção de compras online, os quais são os supermercados Comper, Hippo e Angeloni. Além disso, por ser Florianópolis uma capital, ela apresenta recursos que em cidades menores ou afastadas de grandes centros não apresentariam, como uma infraestrutura completa para o comércio eletrônico.

Definidos os supermercados 1,2 e 3 como objetos de estudo, foi especificado o método de avaliação de interface. Definiu-se, então, trabalhar com avaliação de inspeção, a qual possibilitou uma análise da interface de acordo com as seguintes abordagens: os objetivos do usuário e os objetos da interface (CYBIS; BETIOL; FAUST, 2010). A avaliação por inspeção foi feita pelo próprio pesquisador e enfocou o ponto de vista do usuário, além da execução das tarefas propostas na interface. Essa avaliação, então, foi definida a partir dos critérios/níveis de interatividade propostos por Rhodes \& Azbell (1985), Rafaelli (1988), Laurel (1991), Sims (1997) e Lemos (1999).

O procedimento para a avaliação de inspeção envolveu (1) a definição de padrões de inspeção a partir da revisão teórica, (2) o exame do sistema interativo utilizando os padrões definidos na primeira etapa, (3) a identificação dos tipos e nível de interatividade da interface observada, e (4) o diagnóstico dos problemas ou barreiras que os usuários podem encontrar durante a interação.

\section{AVALIAÇÃO DE INTERFACES}

A listagem com os seguintes itens representam as ações que podem ser realizadas pelo usuário na interface de casa site de e-commerce.

No site do supermercado 1 é possível: navegar pelo site utilizando o menu; verificar a seção atual do site visualizando o caminho de migalhas (caminho da navegação); buscar um produto pelo nome; buscar ajuda de atendente; solicitar imagem ampliada do produto; solicitar mais informações sobre o produto; solicitar informações como descrição, tabela nutricional e composição do produto; escolher a quantidade de unidades que deseja comprar do mesmo produto; solicitar a visualização do carrinho de compras; e solicitar a finalização da compra. Essas ações podem ser visualizadas na Figura 5.

Figura 5 - Compra online do Supermercado 1 


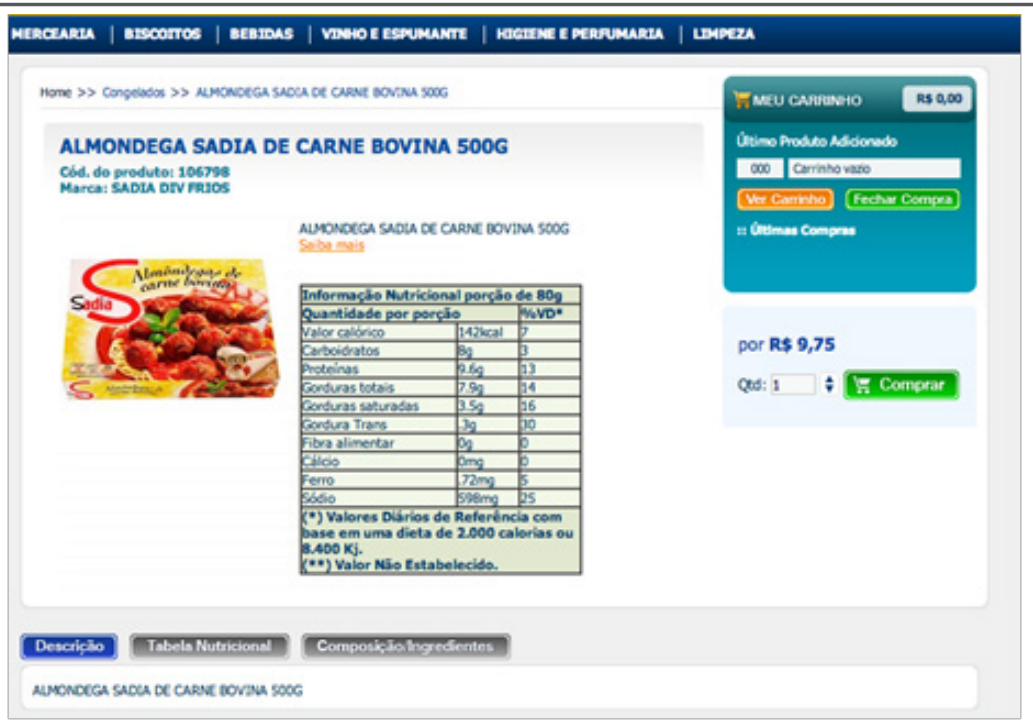

Fonte: Disponível em: http://www.comperdelivery.com.br. Acesso em 01 out. 2012.

No site do supermercado 2 é possível: navegar pelo site utilizando o menu; verificar parcialmente a seção atual do site visualizando o caminho de "migalhas" (KRUG, 2006) ou caminho da navegação (caminho percorrido pelo usuário da página inicial até onde ele se encontra no presente momento da navegação); buscar um produto pelo nome; solicitar outras visualizações do mesmo produto; solicitar informações como descrição do produto; escolher a quantidade de unidades que deseja comprar do mesmo produto; solicitar a visualização da procedência dos produtos; indicar o produto a um amigo; solicitar a visualização do carrinho de compras; comprar; e desistir do produto (botão "voltar"). Essas ações podem ser visualizadas na Figura 6.

Figura 6 - Compra online do Supermercado 2

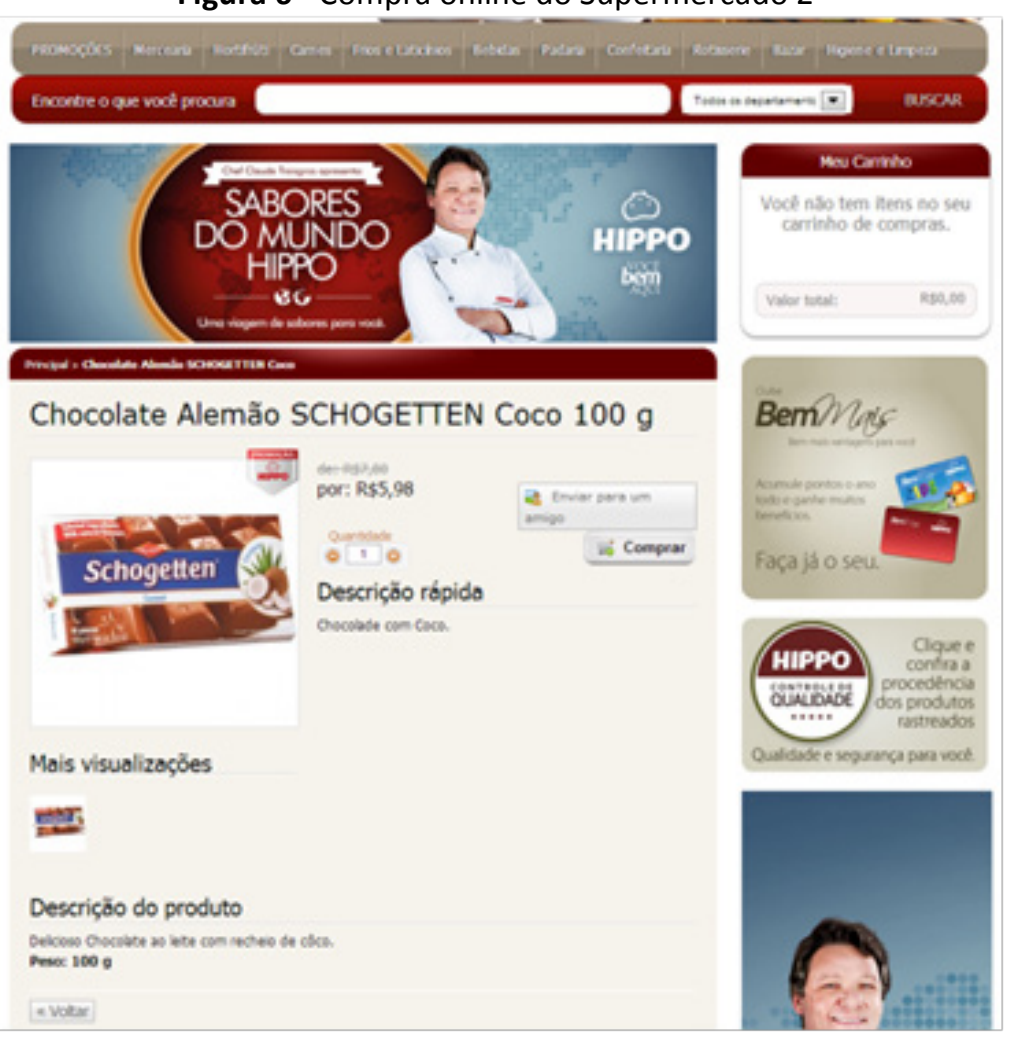

Fonte: Disponível em: http://www.hippo.com.br. Acesso em 01 out. 2012 
No site do Supermercado 3 é possível: navegar pelo site utilizando o menu; verificar a seção atual do site pelo caminho de "migalhas" (caminho da navegação) ou utilizar o caminho de "migalhas" para voltar a uma seção anterior; buscar um produto pelo nome; buscar ajuda de atendente; visualizar sugestões de outros produtos da mesma seção ou "corredor"; escolher a quantidade de unidades que deseja comprar do mesmo produto; "curtir" o produto (divulgá-lo a outras pessoas); conhecer as formas de pagamento; visualizar listas e pedidos; adicionar produto a uma lista já registrada; solicitar a visualização do carrinho de compras; verificar "corredores" e produtos visitados; verificar produtos buscados; visualizar informações de entrega; fazer uma compra rápida; solicitar a finalização da compra; e desistir do produto (botão "voltar"). Essas ações podem ser visualizadas na Figura 7.

Figura 7 - Compra online do Supermercado 3

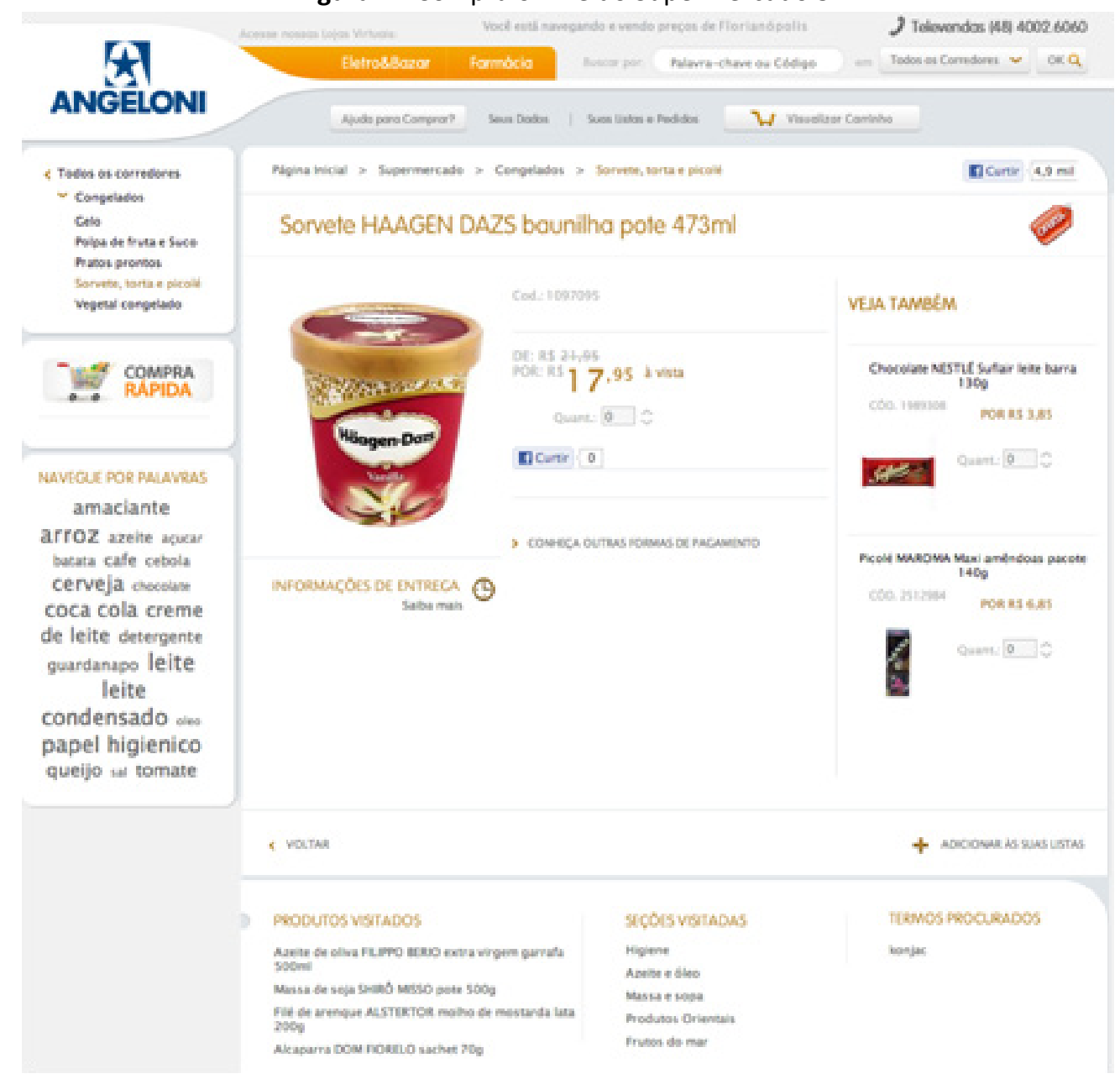

Fonte: Disponível em: http://www.angeloni.com.br. Acesso em 01 out. 2012.

A Tabela 1 faz um comparativo das possíveis ações do usuário na interface digital dos três supermercados observados:

Quadro 1 - Quadro comparativo dos três sites. 
BORTOLÁS Natália ; GONÇALVES Berenice; VIEIRA Milton

\begin{tabular}{|c|c|c|c|}
\hline Ação & Supermercado 1 & Supermercado 2 & Supermercado 3 \\
\hline Navegar & Pelo menu; & Pelo menu; & $\begin{array}{l}\text { Pelo menu; pelo } \\
\text { caminho de "migalhas"; }\end{array}$ \\
\hline Verificar & $\begin{array}{l}\text { Seção atual do site pelo } \\
\text { caminho de "migalhas"; }\end{array}$ & $\begin{array}{l}\text { Parcialmente a seção } \\
\text { atual do site pelo } \\
\text { caminho de "migalhas"; }\end{array}$ & $\begin{array}{l}\text { Seção atual do site pelo } \\
\text { caminho de "migalhas"; } \\
\text { seções visitadas } \\
\text { anteriormente pelo } \\
\text { caminho de "migalhas"; } \\
\text { "corredores" e } \\
\text { produtos visitados. }\end{array}$ \\
\hline Buscar & $\begin{array}{l}\text { Um produto pelo } \\
\text { nome; ajuda de um } \\
\text { atendente }\end{array}$ & $\begin{array}{l}\text { Um produto pelo } \\
\text { nome; }\end{array}$ & $\begin{array}{l}\text { Um produto pelo } \\
\text { nome; ajuda de um } \\
\text { atendente; }\end{array}$ \\
\hline Solicitar/Visualizar & $\begin{array}{l}\text { Imagem ampliada do } \\
\text { produto; Descrição, } \\
\text { tabela nutricional e } \\
\text { composição do } \\
\text { produto; Mais } \\
\text { informações sobre o } \\
\text { produto; Carrinho de } \\
\text { compras; }\end{array}$ & $\begin{array}{l}\text { Outras visualizações do } \\
\text { mesmo produto; } \\
\text { Informações como } \\
\text { descrição do produto; } \\
\text { Procedência do } \\
\text { produto; Carrinho de } \\
\text { compras. }\end{array}$ & $\begin{array}{l}\text { Sugestões de outros } \\
\text { produtos da mesma } \\
\text { seção ou "corredor; } \\
\text { formas de pagamento; } \\
\text { listas e pedidos; } \\
\text { carrinho de compras; } \\
\text { produtos buscados; } \\
\text { informações de } \\
\text { entrega; }\end{array}$ \\
\hline Escolher & $\begin{array}{l}\text { Quantidade de } \\
\text { unidades que deseja } \\
\text { comprar do mesmo } \\
\text { produto; }\end{array}$ & $\begin{array}{l}\text { Quantidade de } \\
\text { unidades que deseja } \\
\text { comprar do mesmo } \\
\text { produto. }\end{array}$ & $\begin{array}{l}\text { Quantidade de } \\
\text { unidades que deseja } \\
\text { comprar do mesmo } \\
\text { produto; Formas de } \\
\text { pagamento; }\end{array}$ \\
\hline Adicionar & - & & $\begin{array}{l}\text { Um produto a uma lista } \\
\text { já registrada. }\end{array}$ \\
\hline Fazer & Compra final. & Compra final. & $\begin{array}{l}\text { Compra rápida; compra } \\
\text { final. }\end{array}$ \\
\hline Divulgar/Indicar & - & $\begin{array}{l}\text { Um produto a um } \\
\text { amigo (por e-mail). }\end{array}$ & $\begin{array}{l}\text { Um produto a um } \\
\text { amigo/amigos (por } \\
\text { rede social). }\end{array}$ \\
\hline Desistir & - & $\begin{array}{l}\text { Quando representado } \\
\text { pelo botão "voltar", a } \\
\text { pessoa pode apenas } \\
\text { desistir de comprar } \\
\text { aquele produto que } \\
\text { está visualizando no } \\
\text { momento. }\end{array}$ & $\begin{array}{l}\text { Quando representado } \\
\text { pelo botão "voltar", o } \\
\text { usuário pode apenas } \\
\text { desistir de comprar } \\
\text { aquele produto que } \\
\text { está visualizando no } \\
\text { momento. }\end{array}$ \\
\hline
\end{tabular}

Uma vez que as possibilidades de interação no site de e-commerce do Supermercado 3 são mais amplas que nos outros dois ambientes virtuais, foi realizada uma avaliação mais detalhada desta interface, a partir dos critérios de classificação da interatividade propostos no tópico dois. Essa avaliação foi desenvolvida em forma de perguntas envolvendo níveis e características da interatividade, potenciais de interação e guias para identificar a existência da interatividade em um ambiente digital.

- $\quad$ Níveis de Interatividade (RHODES \& AZBELL, 1985 apud SIMS, 1997):

o O usuário tem pouco controle na estrutura do conteúdo? Sim.

- O usuário controla a sequência, ritmo e estilo da interface? Apresenta controle sobre a sequência de navegação, mas não sobre o ritmo e o estilo. 
- Apresenta controle sobre estrutura e conteúdo? Não.

Características da Interatividade (RAFAELI, 1988):

- O sistema é bidirecional (funciona em duas direções)? Sim.

- O sistema apresenta resposta imediata, consecutiva ou instantânea? Sim.

- O usuário tem controle sobre a interface, interagindo com esta da forma mais conveniente possível? Não. (Exemplo: o usuário não consegue ampliar a imagem do produto e verificar informações contidas na embalagem, como validade, tabela nutricional etc.

- A ação do usuário tem resposta do sistema? Sim.

- Os hiperlinks são claros e fáceis de serem identificados? Sim. Há consistência visual no planejamento dos links.

- Os caminhos possíveis de navegação são facilmente identificáveis? Sim.

- O sistema pensa e atua racionalmente? Apresenta comportamentos humanos? Não.

Potenciais de Interação (LAUREL, 1991 apud TORI, 2008):

- Em que momentos o usuário pode agir (Frequência)? Pode navegar pelo ambiente virtual a qualquer momento; Realiza escolha e solicitações limitadas, ou seja, pré-concebidas pelo sistema.

- Quantas escolhas o sistema disponibiliza ao usuário (Abrangência)? As escolhas disponibilizadas pelo sistema envolvem, em grande parte, a navegação pelo ambiente. Não existem outras formas de interagir com os elementos, como ampliar imagem do produto, vê-lo de diversos ângulos, ler informações da própria embalagem, criar uma lista pessoal a partir das escolhas dos produtos, incluir informações, reposicionar os elementos da interface de acordo com a conveniência do usuário etc.

- As escolhas do usuário são importantes (Significância)? Sim, entretanto são limitadas e dependentes da programação do sistema.

Guia para identificar a interatividade (SIMS, 1997)

- Existe resposta audio-visual ao acionar um botão ou outro elemento da interface (Interatividade do Objeto)? Sim.

- O usuário está hábil a navegar no ambiente virtual apenas numa sequência linear (Interatividade Linear)? Não. A navegação apresenta característica da nãolinearidade, possibilitando diversos caminhos ao usuário.

- O sistema apresenta suporte às ações desempenhadas pelo usuário (Interatividade de Suporte)? Sim. Entretanto, não é um suporte sensível ao contexto. As mensagens de suporte são simples retornos dados ao usuário quando este solicita um contato (também pré-estabelecido pelo sistema).

- As atualizações (respostas do sistema dada a uma solicitação do usuário) são individualizadas (Interatividade de Atualização)? Não. Tanto as perguntas feitas pelo usuário quanto as respostas do sistema são padronizadas, ou seja, pré-estabelecidas pelo sistema. Assim, a mensagem não pode ser moldada, modificada, impossibilitando a individualização das respostas.

- O usuário tem acesso às informações do sistema, podendo navegar à vontade pela base de conhecimento (Interatividade de Hiperligação)? Sim.

- O conteúdo apresentado no ambiente virtual é bem elaborado, integrando os vários níveis de interatividade e apresentando significado adequado na interface (Interatividade Contextual Não-Imersiva)? Não. Pois não há um planejamento adequado do design de interfaces para este ambiente digital.

o A interface digital proporciona um ambiente interativo do qual o usuário se sente parte? Existem respostas a movimentos e ações individuais do usuário (Interatividade Imersiva Virtual)? Não. 


\section{RESULTADOS E DISCUSSÕES}

A partir da revisão teórica apresentada e da avaliação realizada no site 3 , tendo em vista os parâmetros de interatividade propostos por Rhodes \& Azbell, Rafaelli, Sims, Laurel e Lemos, constatouse que a interatividade presente neste ambiente virtual é voltada para a navegação não-linear, definida por respostas pré-configuradas pelo sistema, sem possibilidade de outras intervenções, ou seja, manipulação da mensagem pelo próprio usuário. Assim, o nível de interatividade do site é classificado como Reativo (RHODES \& AZBELL, 1985 apud SIMS, 1997), pois o usuário não tem controle do ritmo, estilo e tampouco da estrutura e conteúdo do ambiente digital. Por outro lado, o usuário tem controle da sequência das informações, entretanto esse potencial está atrelado à navegação do sistema.

O ambiente também é bidirecional, responde às solicitações do usuário de forma instantânea e é transparente. De outra forma, as opções de interatividade do usuário não são convenientes às suas necessidades e sim às pré-definições do sistema. Apesar de as escolhas do usuário serem importantes, não há abrangência nas opções de interação humano-máquina. O sistema apresenta resposta audiovisual e suporte às ações desempenhadas pelo usuário, mesmo que este suporte seja simples e não exista individualização na mensagem retornada ao usuário.

Entende-se que as possibilidades de interação do sistema estão voltadas essencialmente para a navegação do sistema. Inteligência artificial, interatividade contextual não-imersiva e imersiva não estão presentes no sistema. A individualização na comunicação entre humano e máquina também não são características deste ambiente digital.

Ao passo em que o acesso à internet vem crescendo no Brasil, principalmente em decorrência da evolução da tecnologia móvel (netbooks, smartphones e tablets), as compras online estão se tornando mais populares e necessárias, face à comodidade no acesso à internet realizado de casa e nas compras feitas com cartão de crédito, somado à facilidade de pesquisar produtos e preços na Web. Por outro lado, ao considerar que há uma lacuna no estudo da interatividade, mas que ela é fundamental na interação homem-máquina, são apresentadas algumas sugestões que otimizem a interação humano-computador em sites de e-commerce:

- A fim de tornar a comunicação entre sistema e usuário mais individualizada, podem ser criadas funcionalidades que permitam a inserção de dados pessoais do consumidor, como idade, profissão, estado civil, se tem filhos, se vive sozinho, qual seu estilo de vida etc. Estas informações podem ser usadas pelo sistema, a fim de que as sugestões ou respostas programadas sejam voltadas especificamente para aquele usuário;

- Outra forma de individualizar a comunicação homem-máquina é registrar cada compra realizada pelo consumidor e identificar um padrão na escolha dos produtos. Essa função possibilita que o sistema avise das ofertas do estabelecimento ou sugira a compra de produtos;

- A manipulação das informações pode ser otimizada no momento em que o consumidor está escolhendo um produto que deseja comprar. No estabelecimento físico de um supermercado, os consumidores tem a opção de manusear o produto, verificar seu tamanho, forma, informações nutricionais, ingredientes, entre outros. A fim de tornar essa experiência na Web mais próxima da experiência física, podem ser implementadas aplicações que ofereçam ao usuário ampliar a imagem do produto, girá-lo em qualquer direção e ângulo, visualizar prazo de validade, tabela nutricional, composição e ingredientes.

\section{CONCLUSÃO}

Foi proposto neste artigo identificar os tipos e níveis de interatividade presentes em interfaces de sites de e-commerce, a partir de um método de avaliação por inspeção. Para tanto, a partir da revisão teórica, foram definidos padrões de interatividade, a fim de examinar a interface do ambiente virtual.

Observa-se, face a este estudo, e as avaliações e sugestões que ele proporcionou, que a evolução das mídias digitais e a popularização da internet, formam, juntas, grande potencial para desenvolvimento de produtos interativos. Com isso em mente, espera-se que a pesquisa apresentada tenha contribuído no sentido de explicitar a interatividade como uma característica intrínseca da 
Análise da Interatividade em Sites de E-commerce

interação social, bem como da comunicação entre homem e máquina. Esta, por sua vez, busca no processo humano de comunicação inspiração para otimizar o processo de interação homem-máquina, proporcionado pela interface.

A partir deste trabalho, como estudos futuros, é proposto o desenvolvimento de um guia de identificação dos tipos e opções de interatividade em sistemas online, a fim de sistematizar a avaliação de interfaces no que compete à interatividade entre homem e computador.

\section{REFERÊNCIAS}

AGNER, Luis. Ergodesign e Arquitetura da Informação: trabalhando com o usuário. Rio de Janeiro: Quartet, 2006.

COELHO, Luis Antônio Luzio. (Org.). Conceitos Chave em Design. Ed. PUC-Rio. Novas ideias: Rio de Janeiro, 2008.

CYBIS, Walter; BETIOL, Adriana Holtz; FAUST, Richard. Ergonomia e Usabilidade: Conhecimentos, Métodos e Aplicações. 2ª Ed. São Paulo: Novatec Editora, 2010.

FERRERA, Ruy. Interatividade Educativa em meios digitais: uma visão pedagógica. Tese (doutorado) - Universidade Federal de Campinas. Campinas, SP: 199p, (2008). [Online] Disponível em <http:// content.yudu.com/Library/A1qxfa/InteratividadeEducat/resources/63.htm>. Acesso em 19 de setembro de 2012.

GOMES, Denis dos Santos. Inteligência Artifical: Conceitos e Aplicações. Revista Olhar Científico Faculdades Associadas de Ariquemes - V. 01, n.2, Ago./Dez. 2010. [Online] Disponível em: <http:// www.olharcientifico.kinghost.net/index.php/olhar/article/viewFile/49/37>. Acesso em 30 de set. 2012.

JENSEN, Klaus Bruhn. Interactivity in the Wild: And Empirical Study of Interactivity as Understood in Organizational Practices. Nordicom Review, Göteborg. n.01, 2005. Disponível em: <http://www. nordicom.gu.se/common/publ_pdf/180_003-030.pdf> Acesso em: 19 de set. 2012.

KRUG, Steve. Não me faça pensar: Uma abordagem de Bom Senso à Usabilidade na Web. 2ạ Ed. Rio de Janeiro: Alta Books, 2008.

LEMOS, André. Anjos Interativos e Retribalização do mundo. Sobre interatividade e interfaces digitais. [Online] Disponível em: <http://www.facom.ufba.br/ciberpesquisa/lemos/interativo.pdf >. Acesso em: 12 de set. 2012.

MORAES, Maira de. Produtos Interativos para consumidores multimídia: Discutindo a interatividade na Era dos Bits. Pré Textos (Compós). Salvador: UFBA, 1998.

MOURA, Mônica. Design de Hipermídia: dos princípios aos elementos. São Paulo: Co-edição NMD e Edições Rosari, 2007.

MICHAELIS - Uol. Moderno Dicionário da Língua Portuguesa. 2009. [Online] Disponível em: <http:// michaelis.uol.com.br/>. Acesso em: 01 de out. 2012.

NASSAR, Victor.; PADOVANI, Stefania. Proposta de classificação para níveis de interatividade com foco na construção e compartilhamento de conteúdo. In: Congresso Internacional de Design de Interação, 2011, Belo Horizonte. Anais da 3a Conferência Latino Americana de Design de Interação, v.03, p. 159-168.

PASSOS, Ravi; MOURA, Mônica. Design de Informação na Hipermídia. Rev. Bras. InfoDesign | São 
BORTOLÁS Natália ; GONÇALVES Berenice; VIEIRA Milton

Paulo | InfoDesign | v. 4, n. 2 [2007]. [Online] Disponível em: <http://www.infodesign.org.br/revista/ public/journals/1/No.2Vol.4-2007/ID_v4_n2_2007_20_28_Passos_et_al.pdf?download=1 $>$. Acesso em: 18 de junho de 2011.

PRIMO, Alex Fernando Teixeira; CASSOL, Marcio Borges Fortes. Explorando o conceito de interatividade: definições e taxonomias. Informática na Educação: teoria e prática. v.2, n.2, p.65-80, 1999. [Online] Disponível em: <http://seer.ufrgs.br/InfEducTeoriaPratica/article/view/6286/3756>. Acesso em 19 de setembro de 2012.

RAFAELI, Sheizaff. Interactivity: From New Media to Communication. 1988. [Online] Disponível em:

<http://gsb.haifa.ac.il/ sheizaf/interactivity/Rafaeli_interactivity.pdf > Acesso em: 24 de agosto de 2012. Cap. 4, p. 110-134.

REDIG, Joaquin. Não há cidadania sem informação, nem informação sem design. Rev. Bras. InfoDesign | São Paulo | InfoDesign | v. 1, n. 1 (2004). [Online] Disponível em: <http://www.infodesign.org.br/ revista/public/journals/1/No.1Vol.12004/InfoDesign_v1_n1_2004_04_Redig.pdf?download=1>. Acesso em: 18 de junho de 2011.

ROCHA, Heloisa Vieira da.; BARANAUSKAS, Maria Cecília Calani. Design e Avaliação de Interfaces Humano-Computador. Instituto de Computação. Universidade Estadual de Campinas, 2003. [Online] Disponível em: <http://pan.nied.unicamp.br/download_livro/livrodownload.html>. Acesso em $01 \mathrm{de}$ outubro de 2012.

SANTAELLA, Lúcia. Navegar no ciberespaço: O perfil cognitivo do leitor imersivo. São Paulo: Paulus, 2004.

SCHWIER, Richard; MISANCHUCK, Earl. Interactive multimedia instruction. Educational Technology Publications, Inc. Englewood Cliffs, New Jersey, 1993. [Online] Disponível em: < http://books.google. com.br/books?id=q9HKqrx-7o4C\&printsec=frontcover\&hl=pt-BR\&source=gbs_ge_summary_r\&cad= $0 \# v=$ onepage\& $q \& f=f a l s e ~>$. Acesso em 15 de setembro de 2012.

SIMS, Roderick. Interactivity: a Forgotten Art?. Faculty of Education. University of Technology, Sydney. 1997. [Online] Disponível em: <http://www2.gsu.edu/ wwwitr/docs/interact/>. Acesso em: 12 de setembro de 2012.

TORI, Romero. Games e Interatividade: em busca da felicidade. In: Estéticas Tecnológicas: novos modos de sentir. Santaella, Lucia; Arantes, Priscilla. (Org 